Original Research Article

\title{
To study the prescriptions of the bed-head tickets of inpatients of the selected depts. of JNIMS hospital about the appropriateness of the prescriptions in geriatric patients
}

\author{
Oinam Joychandra Singh, Surbala L., S. Losica R. K.*
}

Department of Pharmacology, JNIMS, Porompat, Imphal795001, Manipur, India

Received: 12 September 2017 Accepted: 03 October 2017

*Correspondence to:

Dr. S. Losica R. K.,

Email: lul.amethystlu.rk@ gmail.com

Copyright: () the author(s), publisher and licensee Medip Academy. This is an openaccess article distributed under the terms of the Creative Commons Attribution NonCommercial License, which permits unrestricted noncommercial use, distribution, and reproduction in any medium, provided the original work is properly cited.

\begin{abstract}
Background: Polypharmacy is an increasing problem among the health care providers. This happened during the management of old age people with much comorbidity and weak functioning of the vital organs like heart, lungs and kidneys, etc. Over and above this, self-medication and adverse drug effects of using many drugs are the causes of polypharmacy. Age 65 years or above is considered as Geriatric.

Methods: 550 case sheets or Bed head tickets of the inpatients of selected departments were examined for a period of three months. 434 bed head tickets having discharge slips with written prescriptions of 5 or more drugs were reexamined as it fulfilled the criteria of Polypharmacy or inappropriate prescriptions. Demographic data, clinical and drug history were recorded in the prepared data sheet. These data were studied as per guidelines of the tools-Beer's criteria, STOPP criteria, START criteria, MAI criteria.

Results: Accordingly, the reasons for polypharmacy and inappropriate prescriptions were elicited. The common drugs mostly prescribed are antibiotics and NSAIDs preparations. The status of polypharmacy or inappropriate prescription were more in the age group of 65-75 years and also mainly among the male geriatric patients. The maximum number of comorbidity was observed in the age group 65-75 years.

Conclusions: As per the criteria of the tools, the number of overprescribing was $70(19.15 \%)$, inappropriate prescription as $17(4.6 \%)$. For prevention and decreasing the incidence of polypharmacy or inappropriate prescriptions, the tools (Beer's criteria, STOPP criteria, START criteria, MAI criteria) are nowadays put forward to the prescriber as a guideline of good and appropriate prescription. Therefore, the present study can find out the status of prescription i.e. under-prescription, over-prescription, avoid prescription and inappropriate prescription. Hence, the study can draw the attention of the prescribers before and during prescribing drugs to the patients particularly old age patients.
\end{abstract}

Keywords: Comorbidities, Discharge slips, Geriatrics, Inappropriateness, Polypharmacy, Prescription

\section{INTRODUCTION}

The writing of the good and appropriate prescription is the main indication of the good management of the patient. The practice of writing of good and appropriate prescription depends on the correct diagnosis of the disease on the basis of the clinical findings and laboratory investigations and also the decision taken by the treating doctors. If the drugs in the prescription are doing good to the patients, then the use of the drug indicate the use of multiple drugs by the patient. In this study, polypharmacy is considered if the patient receives five or more concurrent medications by administration of drugs during health care by the health care providers particularly in geriatric (60years and above). ${ }^{1}$ Recently those individual of 65years and above are considered as geriatric. ${ }^{2}$ About $12 \%$ of the Indian population is geriatric. ${ }^{2}$

Longer life expectancy, comorbidity and the treatment of adverse drug effects (ADEs) paved the way for polypharmacy. Polypharmacy in geriatric is becoming a big problem because it is associated with greater health care costs, substantial risk of ADEs, drug-drug interaction, medication non-compliance, decreased functional activity 
reduces functional capacity and can increase the prevalence of drug associated morbidity and mortality., ${ }^{1,2}$ Therefore, different tools i.e. Beer's criteria, STOPP (Screening tool of older person's prescriptions) criteria, START (Screening tool to alert to right treatment) criteria, MAI (Medication appropriate index) criteria are proposed for discouraging of polypharmacy, overpharmacy and underpharmacy. ${ }^{3,4}$ The objectives of the study was to study the appropriateness of prescriptions among the geriatric patients of selected inpatients depts. of tertiary health institutions as per the guideline of Beer's criteria, STOPP criteria, START criteria and MAI criteria.

\section{METHODS}

550 bed head tickets (BHTs) of the inpatients of selected depts. (medicine, ophthalmology, orthopaedic, psychiatry and surgery) for the period i.e. September to November 2016 were recruited from the medical Record Dept. of JNIMS after obtaining permission of the Medical Superintendent and Medical Record Officer of JNIMS Hospital. Out of 550 BHTs, 434 BHTs were screened again. Data regarding the patient's demographics, clinical and drug history were obtained from the BHTs as per the already prepared data sheet. Vitamins, minerals, herbs, alternative medicine were excluded as they are difficult to analyse their appropriateness. ${ }^{1}$ The remaining medicines which were received by the patients e.g. five or more drugs were considered as polypharmacy. ${ }^{1}$ Appropriateness of the medication for each patient was analysed separately on the basis of clinical findings reflected in the BHT as per the guidelines of MAI (Medication appropriate index), Beer's criteria, STOPP criteria, START criteria. (Table 1).

Table 1: Different tools for assessing the appropriateness of the prescriptions.

\begin{tabular}{|ll|}
\hline Criteria & Descriptions \\
\hline MAI criteria & Indications and effectiveness of drugs, duplications of drugs \\
\hline STOPP criteria & 65 criteria under different physiological conditions \\
\hline START criteria & 23 criteria under different physiological conditions \\
\hline Beer's criteria & Classify drugs as appropriate or inappropriate \\
\hline & 53 inappropriate medication \\
\hline & 24 drugs to be avoided \\
\hline & 5 medications with cautions \\
\hline
\end{tabular}

Sample size was calculated on the basis of the expected proportion of people aged 65years and above conceiving polypharmacy. Taking $10 \%$ as relative precision at $90 \%$ power and confidence level $95 \%$, the sample size was found 347 and by adding $20 \%$ as non-responder, the final sample size comes to be 434 geriatric patients.

\section{Statistical analysis}

Descriptive statistics, continuous variables ( $\mathrm{t}$ test), categorical variable (chi square test), Pearson correlation and correlate between different parameters are examined and analysed by using SPSS.

\section{RESULTS}

550 case sheets or bed-head tickets (BHTs) of the inpatients of the selected depts. (medicine, ophthalmology, orthopaedic, psychiatry and surgery) were recruited from the Medical Record Dept. of JNIMS because the depts. treated maximum number of old age patients.

The case sheets of the 434 BHTs were examined on the basis of clinical findings and investigation report and also comorbidity etc. The discharge slips of 434 BHTs were again examined, out of which, only 366 (84\%) discharge slips showed polypharmacy. Only 125 (34\%) discharged slips showed the prescription of 5 (five) drugs. The gender and age group is shown in the Table 3.

Table 2: Gender and age distribution among the geriatric patients in the study.

\begin{tabular}{|ll|}
\hline Demographics & n (\%) \\
\hline Gender & \\
\hline Male & $187(51.70)$ \\
\hline Female & $176(48 \%)$ \\
\hline Age distribution (years) & \\
\hline $65-75$ & 259 \\
\hline $76-85$ & 78 \\
\hline $86-95$ & 26 \\
\hline$>96$ & 3 \\
\hline
\end{tabular}

The status of polypharmacy was also assessed and shown as in Table 3. The number of discharge slip having prescription containing antibiotic drugs was 334 (91\%). The polypharmacy was associated with much comorbidity. The number of polypharmacy with the comorbidity was $163(44.5 \%)$. The comorbidity is on the rise when individual gets older because of multiple organ disability and illness. The number of comorbidities was also examined as in Table 4. Lastly, only 116 discharge slips showed non-polypharmacy i.e. may be appropriate or under polypharmacy. 
Table 3: Status of polypharmacy.

\begin{tabular}{|llll|}
\hline No. of drugs & All patient's frequency, $\mathbf{n}(\%)$ & Male patient's frequency, $\mathbf{n}(\%)$ & Female patient's frequency, $\mathbf{n}(\%)$ \\
\hline 5 & $125(34 \%)$ & $69(18.8 \%)$ & $56(15.3 \%)$ \\
\hline 6 & $83(22.3 \%)$ & $37(10.1 \%)$ & $46(12.5 \%)$ \\
\hline 7 & $52(14.2 \%)$ & $32(8.7 \%)$ & $20(5.4 \%)$ \\
\hline 8 & $47(12.8 \%)$ & $17(4.6 \%)$ & $30(8.19 \%)$ \\
\hline 9 & $23(6.2 \%)$ & $14(3.8 \%)$ & $9(2.45 \%)$ \\
\hline 10 & $12(3.2 \%)$ & $5(1.36 \%)$ & $7(1.71 \%)$ \\
\hline$>10$ & $24(6.5 \%)$ & $16(4.3 \%)$ & $8(2.1 \%)$ \\
\hline
\end{tabular}

Among the comorbidity, DM (Diabetes Mellitus) is $43(\%)$, HTN (Hypertension) 58 (\%), RD (Respiratory Disease) 52 (\%), CVS (Cardiovascular) 64 (\%), CNS (Central Nervous system) 16 (\%), CLD (Chronic Liver Disease) 7(\%), CKD (Chronic Kidney Disease) $11(\%)$, Cancer $1(\%)$, Msk Musculoskeletal $5(\%)$, others $5(\%)$ as shown in Table 5. They are statistically significant.

Table 4: Sex and age group-wise distribution of elderly patients based on the number of comorbidities.

\begin{tabular}{|c|c|c|c|c|c|c|c|}
\hline \multirow[t]{3}{*}{$\begin{array}{l}\text { Number of } \\
\text { comorbidities }\end{array}$} & \multicolumn{4}{|l|}{ Male } & \multicolumn{3}{|l|}{ Female } \\
\hline & \multicolumn{4}{|c|}{ Age category, $n$} & \multicolumn{3}{|c|}{ Age category, $n$} \\
\hline & $\begin{array}{l}\text { 65-75 years } \\
(n=70)\end{array}$ & $\begin{array}{l}\text { 76-85 year } \\
(\mathrm{n}=15)\end{array}$ & $\begin{array}{l}\text { 86-95 years } \\
(n=8)\end{array}$ & $\begin{array}{l}>96 \text { years } \\
(n=1)\end{array}$ & $\begin{array}{l}\text { 76-85 years } \\
(n=25)\end{array}$ & $\begin{array}{l}\text { 86-95 years } \\
(\mathrm{n}=2)\end{array}$ & $\begin{array}{l}>96 \text { years } \\
(n=0)\end{array}$ \\
\hline 1 & 2 & 0 & 0 & 0 & 0 & 0 & 0 \\
\hline 2 & 10 & 2 & 1 & 0 & 3 & 0 & 0 \\
\hline 3 & 15 & 3 & 2 & 0 & 10 & 1 & 0 \\
\hline 4 & 43 & 10 & 5 & 1 & 12 & 1 & 0 \\
\hline $\mathrm{r}$ & 0.92 & 0.91 & 0.95 & 0.77 & 0.97 & 0.89 & - \\
\hline
\end{tabular}

Table 5: Distribution of comorbidities among different age groups in geriatric patients receiving polypharmacy.

\begin{tabular}{|c|c|c|c|c|c|}
\hline \multirow[t]{2}{*}{ Comorbidities } & \multirow[t]{2}{*}{$\begin{array}{l}\text { Total number of patients with } \\
\text { comorbidities receiving polypharmacy }\end{array}$} & \multicolumn{4}{|c|}{ Age category, n } \\
\hline & & 65-75 years & 76-85 years & 86-95 years & $>96$ years \\
\hline DM & $43^{*}$ & 36 & 5 & 1 & 1 \\
\hline RD & $52^{*}$ & 28 & 20 & 4 & 0 \\
\hline HTN & $58^{*}$ & 46 & 10 & 2 & 0 \\
\hline CVS & $64^{*}$ & 42 & 17 & 5 & 0 \\
\hline CLD & $7^{*}$ & 7 & 0 & 0 & 0 \\
\hline CNS & $16^{*}$ & 11 & 5 & 0 & 0 \\
\hline CKD & $11^{*}$ & 9 & 1 & 1 & 0 \\
\hline Msk & $5^{*}$ & 3 & 1 & 1 & 0 \\
\hline Cancer & $1^{*}$ & 1 & 0 & 0 & 0 \\
\hline Others & $5^{*}$ & 5 & 0 & 0 & 0 \\
\hline
\end{tabular}

$* \mathrm{p}<0.001$ (chi-square test) polypharmacy versus comorbidities

The findings drew the attention of the prescribers that the tools will be useful as a guidance in future as Rakesh et al in their study showed $39(9.1 \%)$ overprescribing, 56 $(13.1 \%)$ under use of medicine and 85 (19.9\%) as inappropriate prescription. ${ }^{1}$ The overprescribing, inappropriate use of drugs was more in male geriatric patients, the difference in patients' characteristics, prescribing patterns and assessment may be responsible for the variation seen in the prevalence of inappropriate prescription in various studies. A geographical variation among the physician's awareness and attitude of the physician towards practice is a cause of inappropriate prescription. 
Table 6: Status of prescription according to tools.

\begin{tabular}{|lllll|}
\hline Groups & Drugs to avoid & Overprescribing & Under-prescribing & Inappropriate prescribing \\
\hline All Patients, $n$ & 2 & 70 & 11 & 17 \\
\hline Male, $\mathrm{n}$ & 1 & 41 & 4 & 6 \\
\hline Female, $\mathrm{n}$ & 1 & 29 & 7 & 11 \\
\hline P* & 1 & 0.151 & 0.365 & 0.225 \\
\hline
\end{tabular}

*Chi-square test (inappropriate prescriptions, male versus female)

\section{DISCUSSION}

Patients whose age is 65years and above is considered as geriatric patients and in some other conditions those patients whose age is 60years and above is also considered elderly or geriatric patients. ${ }^{1,2}$ About $12 \%$ of the Indian population is geriatric. ${ }^{2}$ This group of people when they are not well or fall illness, they consumed a large number of drugs for the management of their disease or their comorbidity conditions. The multidrug consumption may be according to the treating doctors or as per the personal medications. ${ }^{1}$ When they themselves consumed 5 drugs or more or asked to take 5 drugs or more by the treating doctors the condition is called polypharmacy or a prescription of polypharmacy. ${ }^{1,2}$ Sometime the polypharmacy happened according to the nature of the disease (e.g. TB). ${ }^{2}$ This polypharmacy is the therapeutic polypharmacy. ${ }^{1}$ Such prescription is not considered in this study. The contra-therapeutic polypharmacy also happened when there is ADE's. ${ }^{5,6}$ Polypharmacy has many impacts on ADEs, resistant development, drug interaction, economic factors. ${ }^{6-8}$ The present study showed on the basis of the basis of the guidelines of the tools, Beers criteria, STOPP criteria, START criteria, MAI criteria. ${ }^{9,10}$

The mean age of the patient was $73 \pm$ (male 75 , female 71 ) and the common drugs which were consumed by the patients was PPI (58.2\%), Antibiotics (71\%), NSAIDS (57\%), CVS $(33.1 \%)$. The overall percentage of the patients receiving five or more was $84 \%$. The prevalence of polypharmacy obtained was 84\% (366/434) in the present study whereas the findings of Slabaugh et al, was $39.4 \%$ and the percentage of polypharmacy was found more in males than females. ${ }^{11}$ When examining the factor, the present study showed a high occurrence of polypharmacy in the age group 65-75years. The finding supported the observation of the study of Rakesh et al, Dutta and Prasad. ${ }^{1,8}$ The occurrence is higher in age group $70-79(81.6 \%)$. When referring to Beer's criteria, this study observed two $(0.54 \%)$ patients received avoidable prescription but according to Chung et al, $27.8 \%$ patients received avoidable prescription. ${ }^{12}$ On further examination, as per the guidelines of the tools, the study showed 70 $(19.1 \%)$ over prescribing, $11(3 \%)$ under-prescribing and $17(4.6 \%)$ inappropriate prescription. The main reasons of polypharmacy are the association of comorbidities mainly DM (43\%), HTN (58\%), CNS (16\%). These findings supported Al Ameri et al, the above-mentioned criteria were used by the researchers and policy makers for regulating the disadvantages of polypharmacy and inappropriateness of prescription. These criteria's may also alert the prescribers and help in reducing the chances of prescribing inappropriate drugs.

\section{CONCLUSION}

Polypharmacy is a problem of substantial importance in terms of both direct and indirect medication costs resulting from drug related morbidity. The findings may bring a suggestion for the physicians, clinical pharmacist, that a potential for combating this problem of polypharmacy through a variety of interventions i.e. reconcile medications upon discharge slips of hospital and skilled nursing facilities reducing the number of medication taken, reducing the number of drug taken, increasing patient's adherence, preventing ADR's, improving patient's quality of life, decreasing drug costs.

\section{ACKNOWLEDGEMENTS}

Authors would like to thank The Medical Superintendent and the Medical Record Officer JNIMS Hospital.

Funding: No funding sources

Conflict of interest: None declared

Ethical approval: The study was approved by the Institutional Ethics Committee

\section{REFERENCES}

1. Rakesh KB, Chowta MN, Shenoy AK, Shastry R, Pai SB. Evaluation of polypharmacy and appropriateness of prescription in geriatric patients: A cross-sectional study at a tertiary care hospital. Indian Journal of Pharmacology. 2017 Jan;49(1):16-20.

2. Maiti R. Polypharmacy-Postgraduate $t$ topics in pharmacology: $2^{\text {nd }}$ edn. Publishers-Paramedical books. 2015:270-276.

3. O'Mahony D, Gallagher $\mathrm{P}$, Ryan C, Byrne S, Hamilton H, Barry P, O’Connor M, Kennedy J. STOPP and START criteria: a new approach to detecting potentially inappropriate prescribing in old age. European Geriatric Medicine. 2010 Feb 28;1(1):45-51

4. O'mahony D, O'sullivan D, Byrne S, O'connor MN, Ryan C, Gallagher P. STOPP/START criteria for potentially inappropriate prescribing in older people: version 2. Age and ageing. 2015 Mar 1;44(2):213-8. 
5. Gallagher PF, O'Connor MN, O’Mahony. Prevention of potentially inappropriate prescribing for elderly patients: A randomized controlled trial using STOPP/START criteria. Clinical Pharmacology Therapeutic. 2011;89:895-954.

6. Al Ameri MN, Makramalla E, Albur U, Kumar A, Rao P. Prevalence of polypharmacy in elderly. Implications of Age, Gender, Comorbidities and Drug Interactions: J Pharm sciences. 2014;1:1-7.

7. Pradhan S, Panda A, Mohanty M, Behera JP, Ramani YR, Pradhan PK. A study of the prevalence of potentially inappropriate medication in elderly in a tertiary care teaching hospital in the state of Odisha. Int J Med Public Health. 2015;5:344-8.

8. Dutta M, Prashad L. Prevalence and Risk Factors of Polypharmacy among elderly in India, evidence from SAGE data. Int $\mathbf{J}$ Public Mental Neuro Sci. 2015(2);2394-4668.

9. John NN, Kumar AN. a study on polypharmacy in senior. Indian population. Int J Pharma Chem Bio Sci. 2013(3):168-71.
10. O'connor MN, Gallagher P, O'Mahony D. Inappropriate prescribing criteria detection and prevention: Drugs Ageing. 2012;19:437-52.

11. Slabaugh SL, Maio V, Templin M, Abouzaid S. Prevalence and Risk of Polypharmacy among the Elderly in an Outpatient Setting. Drugs and Aging. 2010 Dec 1;27(12):1019-28.

12. Chung H, Suh Y, Chon S, Lee E, Lee BK, Kim K. Analysis of inappropriate medication use in hospitalised geriatric patients: J Korean Soc Health System Pharma. 2007;24:115-23.

Cite this article as: Singh OJ, Surbala L, Losica RKS. To study the prescriptions of the bed-head tickets of inpatients of the selected depts. of JNIMS hospital about the appropriateness of the prescriptions in geriatric patients. Int $\mathrm{J}$ Basic Clin Pharmacol 2017;6:2707-11. 